\title{
Dichotomous scoring of TDP-43 proteinopathy from specific brain regions in 27 academic research centers: associations with Alzheimer's disease and cerebrovascular disease pathologies
}

\author{
Yuriko Katsumata ${ }^{1,2^{*}}$ (D), David W. Fardo ${ }^{1,2}$, Walter A. Kukull ${ }^{3}$ and Peter T. Nelson ${ }^{2,4}$
}

\begin{abstract}
TAR-DNA binding protein 43 (TDP-43) proteinopathy is a common brain pathology in elderly persons, but much remains to be learned about this high-morbidity condition. Published stage-based systems for operationalizing disease severity rely on the involvement (presence/absence) of pathology in specific anatomic regions. To examine the comorbidities associated with TDP-43 pathology in aged individuals, we studied data from the National Alzheimer's Coordinating Center (NACC) Neuropathology Data Set. Data were analyzed from 929 included subjects with available TDP-43 pathology information, sourced from 27 different American Alzheimer's Disease Centers (ADCs). Cases with relatively unusual diseases including autopsy-proven frontotemporal lobar degeneration (FTLD-TDP or FTLD-tau) were excluded from the study. Our data provide new information about pathologic features that are and are not associated with TDP-43 pathologies in different brain areas-spinal cord, amygdala, hippocampus, entorhinal cortex/inferior temporal cortex, and frontal neocortex. Different research centers used cite-specific methods including different TDP-43 antibodies. TDP-43 pathology in at least one brain region was common (31.4\%) but the pathology was rarely observed in spinal cord (1.8\%) and also unusual in frontal cortex (5.3\%). As expected, TDP-43 pathology was positively associated with comorbid hippocampal sclerosis pathology and with severe AD pathology. TDP-43 pathology was also associated with comorbid moderate-to-severe brain arteriolosclerosis. The association between TDP-43 pathology and brain arteriolosclerosis appears relatively specific since there was no detected association between TDP-43 pathology and microinfarcts, lacunar infarcts, large infarcts, cerebral amyloid angiopathy (CAA), or circle of Willis atherosclerosis. Together, these observations provide support for the hypothesis that many aged brains are affected by a TDP-43 proteinopathy that is more likely to be seen in brains with AD pathology, arteriolosclerosis pathology, or both.
\end{abstract}

Keywords: FTD, VCID, Arteriosclerosis, Apolipoprotein E

* Correspondence: katsumata.yuriko@uky.edu

'Department of Biostatistics, University of Kentucky, 725 Rose Street, Lexington, KY 40536, USA

${ }^{2}$ Sanders-Brown Center on Aging, University of Kentucky, Lexington, KY

40536, USA

Full list of author information is available at the end of the article

(c) The Author(s). 2018 Open Access This article is distributed under the terms of the Creative Commons Attribution 4.0 International License (http://creativecommons.org/licenses/by/4.0/), which permits unrestricted use, distribution, and reproduction in any medium, provided you give appropriate credit to the original author(s) and the source, provide a link to the Creative Commons license, and indicate if changes were made. The Creative Commons Public Domain Dedication waiver (http://creativecommons.org/publicdomain/zero/1.0/) applies to the data made available in this article, unless otherwise stated. 


\section{Introduction}

There is an evolving appreciation of a common brain disease with TAR-DNA binding protein 43 (TDP-43) proteinopathy that mimics Alzheimer's disease (AD) clinically $[5,25,26,34,39,50]$ and affects $10-25 \%$ of persons aged 85 or older [5, 19, 21, 33, 50]. The defining characteristics of this disease are recognized by neuropathologic observations: TDP-43 pathology, often with comorbid neuronal loss and astrocytosis pathology in the hippocampus [1, 33], the latter two features collectively termed hippocampal sclerosis (HS). The literature that pertains to this disease was initially focused on HS pathology (TDP-43 pathology was discovered as a disease marker in 2006 [38]), but it is now recognized that TDP-43 pathology is the most sensitive and specific marker of the disease. For example, cases with HS pathology due to acute anoxia is immunonegative for TDP-43 and is considered a fundamentally different disease [2, 20, 33]. Importantly, the presence of TDP-43 proteinopathy, with or without comorbid HS pathology, is independently associated with cognitive impairment $[5,26,29,31]$.

"TDP-43 pathology" lacks a universally applied specific connotation, but refers to phosphorylated TDP-43 deposits in cytoplasmic (where it may appear like speckles, skeins, or tangles), intranuclear, perivascular, and/or neurite-like structures. TDP-43 pathology may also manifest as a decrease in the normal (non-phosphorylated) TDP-43 in the nucleus [4], or within twig-like deposits of phosphorylated TDP-43 detected immunohistochemically in the subpial or subependymal regions $[11,18,30]$. In prior published papers that have studied the spectrum of TDP-43 pathologies in aged brains (often with comorbid AD pathology), the severity of TDP-43 proteinopathy has been mostly graded according to stage-based classification systems where the presence of any TDP-43 pathology in a given region defines a particular stage [15, 17, 27, 29, 44]. For example, the amygdala seems to be affected very early so this is the first stage. By contrast, in cases with extensive pathology, the frontal neocortex may be affected and if this region has any detectable TDP-43 pathology, that is indicative of a late disease stage. Unfortunately, there currently is no consensus as to a specific antibody or combination of antibodies recommended for detecting TDP-43 proteinopathy. Further, the stage-based classification systems for common age-related disease differ from TDP-43 pathologic staging systems that were developed for amyotrophic lateral sclerosis (ALS) and/or frontotemporal lobar degeneration (FTLD)-TDP [6, 10, 45].

Prior published findings suggest that vascular factors may cause or exacerbate the disease process that manifests neuropathologically as TDP-43 (with or without HS pathology) in the aged brain [8, 41, 47, 49]. In prior work, arteriolosclerosis - dysmorphic changes in small arterioles - was preferentially associated with this disease [36]. Further, arteriolosclerosis was observed in regions outside of the hippocampal formation in cases with comorbid HS pathology, indicating a "whole-brain disease" rather than a disease process isolated to the medial temporal lobe [37]. However, the precise underlying mechanisms are not understood, and more work is required to determine how the clinical and pathologic endpoints are associated with each other.

The AD Centers (ADCs) program has constituted a critical resource for research on AD and related dementias in the U.S. This network derived from a National Institutes of Health (NIH)-funded initiative that started in 1984 and has included more than 30 different ADCs geographically dispersed across the U.S. Each ADC follows a longitudinal cohort of generally elderly individuals reflecting a broad spectrum of clinical diseases and pathologic manifestations. The National Alzheimer's Coordinating Center (NACC) oversees data collection by the ADCs. For research subjects that died and came to autopsy, a standardized form was created by NACC to describe the neuropathology in a systematic manner, and for correlation with clinical, radiographic, genetic, and biochemical parameters in the same persons. The latest Neuropathology (NP) Form was updated in 2014, and is referred to as version 10 (v10). The NACC NP Form v10 incorporated detailed neuropathological data including Thal phase for $\mathrm{A} \beta$ plaques [43], relatively newly categorized FTLD neuropathologic changes [23], ALS/motor neuron disease (MND), HS of the CA1 and/ or subiculum, and distributions of TDP-43 immunoreactive inclusions in five brain regions. The summary data for the updated v10 form was recently described [3]. Here we focused on the clinical and pathologic correlates of TDP-43 pathology in the NACC NP v10 data set among individuals lacking unusual conditions such as FTLD.

\section{Materials and methods Participants}

For the current study, data (before exclusion criteria were applied) derived from 30 different ADCs with autopsies reported using the NACC NP v10 form, which started in 2014, through the data freeze of July 11th 2018. Autopsies were performed within each of the contributory ADCs. The database comprises a standardized set of data collected based on the NACC NP v10 data collection form (https://www.alz.washington.edu/NON MEMBER/NP/rdd_np.pdf). Inclusion criteria for this study were neuropathology data available through the NACC NP Form v10, age at death $\geq 65$ years, and non-missing data on TDP-43 referent to at least one of the five brain regions of interest (see below). Exclusion criteria were the presence of at least one of 19 rare 
neurological diseases (see Additional file 1: Table S1). Research using the NACC database was approved by the University of Washington Institutional Review Board. Informed consent was obtained from all participants at the individual ADCs. The NACC data were de-identified.

\section{Measurements \\ Neuropathology data}

TDP-43-immunoreactive inclusions were evaluated in five brain regions: spinal cord, amygdala, hippocampus, entorhinal cortex/inferior temporal cortex (EC/inferior TCTX), and frontal neocortex, with the response categories "no", "yes", "not assessed", and "missing/unknown". Because data on TDP-43 pathology in spinal cord contained more "not assessed" or "missing/unknown" values (Additional file 1: Table S2), we considered TDP-43 inclusions in four brain regions (all except spinal cord) in the subsequent multivariable regression analyses. HS was determined by the variable of "hippocampal sclerosis of CA1 and/or subiculum" ("unilateral", "bilateral", or "present but laterality not assessed"). Data was obtained from all 30 contributory ADCs on whether the antibody used was phospho-specific or non-phospho-specific. A survey was sent to all the ADC Neuropathology Core leaders as to what specific antibodies were used. The phospho-specific antibodies were mostly 1D3 (EMD Millipore), followed by 11-9 (Cosmo Bio) and the polyclonal Cosmo Bio antibody (TIP-PTD-P02). The non-phospho-specific antibodies were almost all Proteintech 10,782-2-AP (rabbit polyclonal), with one center reporting to use Sigma C-term (T1580). Examples of results from the two most frequently used antibodies are shown in Fig. 1. For AD-related pathology, data were included on density of diffuse plaques ("none", "sparse", "moderate", or "frequent"), density of neocortical neuritic plaques ("none", "sparse", "moderate", or "frequent"), Thal phase for $A \beta$ distribution (Thal $A \beta$ phases 0 to 5), Braak stage for neurofibrillary degeneration (Braak NFT stages 0 to VI). For cerebrovascular pathology, data were available on atherosclerosis severity in the circle of Willis ("none", "mild", "moderate", or severe), cerebral amyloid angiopathy ("none", "mild", "moderate", or "severe"), infarct and lacunes (no or yes), microinfarcts (no or yes), hemorrhages and microbleeds (no or yes), and arteriolosclerosis ("none", "mild", "moderate", or "severe"; see Fig. 2). The detailed response categories of these variables and the dichotomized scoring are shown in Additional file 1: Table S3.

\section{Statistical analysis}

Descriptive statistical analyses were performed for sex, age at death (both available in the NACC NP Form v10), and years of education, apolipoprotein $\mathrm{E}(A P O E)$ genotype (no $\varepsilon 4$ alleles $=0$, one $\varepsilon 4$ allele $=1$, or pair of $\varepsilon 4$ alleles $=2$ ), and other health conditions at the last clinical visit (via self-report) including diabetes, hypertension, hypercholesterolemia, and thyroid disease (all from the NACC Uniform Data Set (UDS)).

Comparisons of characteristics of individuals with and without the TDP-43 pathology were performed using t-tests for continuous variables and Pearson's chi-square test for categorical variables. Multivariable logistic regression was used to examine the associations of TDP-43 pathology with AD and cerebrovascular disease pathologies. We controlled for sex, age at death, $A P O E$ genotype, and the type of TDP-43 antibody in the analyses for AD pathologies, and additionally for Braak NFT stage and Thal $A \beta$ phase in the analyses for cerebrovascular disease pathologies. All statistical analyses were carried out with $R$ version 3.4.4 [40]. Statistical significance was set at 0.05 .

\section{Results}

Subjects who were assessed by ADC neuropathologists using the NACC NP Form v10 and died at age 65 years or older $(n=1968)$ were extracted from the NACC NP dataset. We excluded 476 subjects who had at least one rare neurological disease listed in Additional file 1: Table S1, and we also excluded 562 subjects who had no TDP-43 pathology (i.e., missing) data reported in all five brain regions and 1 subject with "other" reported as the TDP-43 antibody used (Fig. 3). Following exclusions, a total of 929 subjects were included in this study. For these subjects, TDP-43 pathology data were sourced from 27 different ADCs (range of the number of subjects with any TDP-43 pathology in this study: 1-123 cases per center), including ADCs that only recently began to perform autopsies for inclusion in this dataset. The mean number of the subjects analyzed per ADC was 34 (median 33). Overall, $67.3 \%$ of the subjects were stained with phospho-specific antibodies; the rest with non-phospho-specfic antibodies. Among the 20 different ADCs that submitted 10 or more subjects with relevant TDP-43 immunohistochemistry (IHC) data to NACC, 13 ADCs used all or mostly phospho-specific antibodies for TDP-43 IHC, whereas 7 ADCs used all or mostly non-phospho-specific TDP-43 antibodies (Additional file 1: Table S4).

Table 1 shows the characteristics of the study subjects in total and stratified by TDP-43 pathology absent or present in at least one brain region. In all included subjects, the mean (standard deviation (SD)) age at death was 83.1 (8.7), $51.8 \%$ were males, and the mean of years of education was 15.5 (3.1). The subjects with TDP-43 pathology in at least one region died older ( $p$-value < 0.001 ). There were no statistically significant differences 

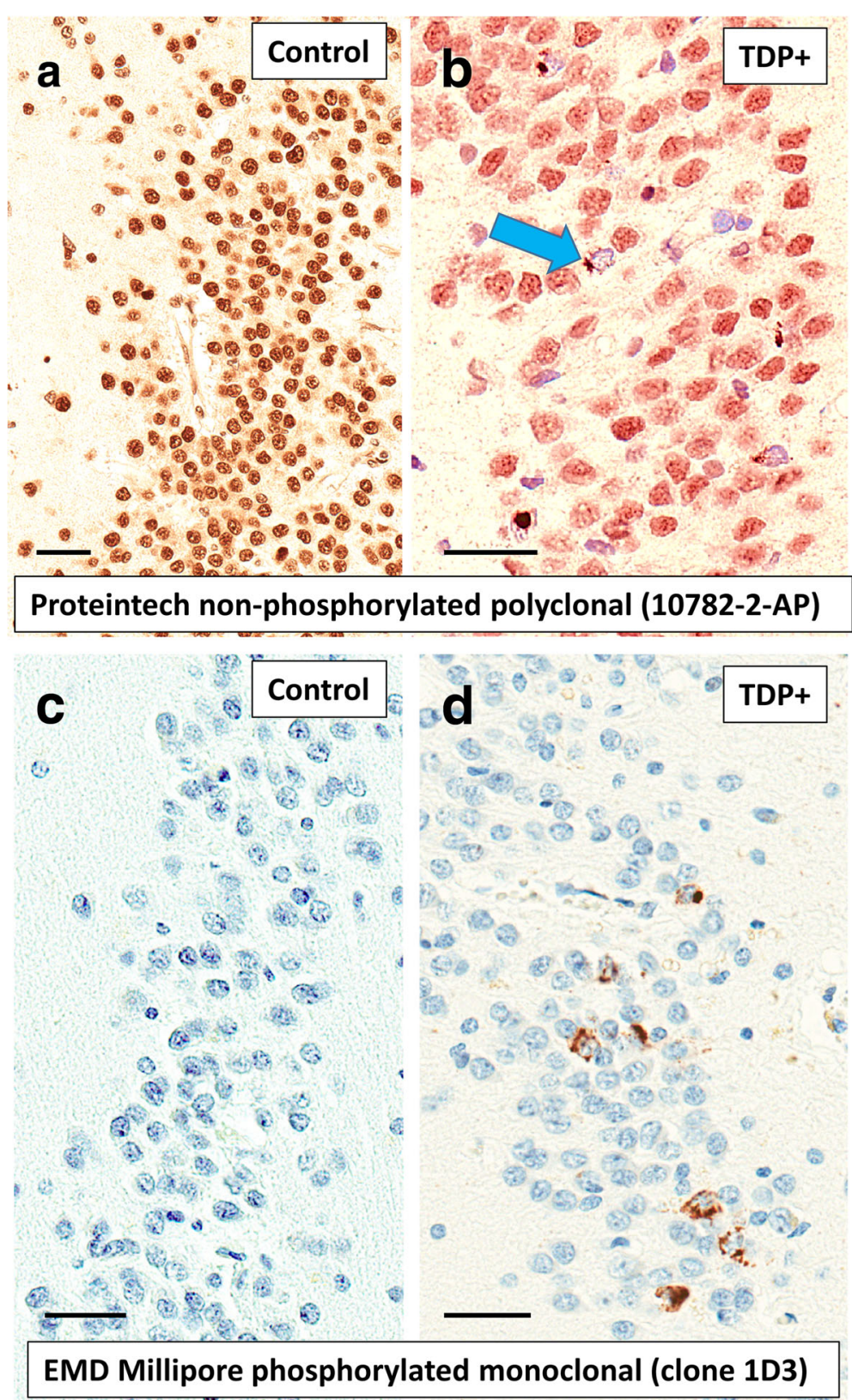

Fig. 1 Examples of TDP-43 immunohistochemistry performed with the most commonly used antibodies against non-phosphorylated TDP-43 (a,b: Proteintech 10,782-2-AP), and phosphorylated TDP-43 (c,d: EMD Millipore clone 1D3) in the Alzheimer's Disease Centers (ADCs) that contribute to the NACC neuropathology dataset. These sections are counterstained with hematoxylin (blue-stained nuclei). Shown are portions of dentate granule cells from the hippocampi of cases without TDP-43 pathology $(\mathbf{a}, \mathbf{c})$ which are contrasted against cases with detectable TDP-43 pathology (b,d). In normal brains, non-phosphorylated TDP-43 protein is seen in cell nuclei (a). In cases with TDP-43 pathology, the non-phosphorylated TDP-43 protein can be seen in some cells' cytoplasm instead of the cell nucleus (b). The antibody against phosphorylated TDP-43 protein shows no brown reaction product in normal brain (c), with only the hematoxylin (blue) counterstain evident. By contrast, there are clearly intracellular aggregates (brown-colored chromagen) of phosphorylated TDP-43 protein in panel $(\mathbf{d})$. Scale bars $=30 \mu \mathrm{m}$

in sex, $A P O E$ genotype, educational attainment, and other health conditions between subjects with and without TDP-43 pathology.

We compared TDP-43 pathology frequencies between HS present and absent in each brain region (Fig. 4). HS pathology was strongly associated with TDP-43 pathology in each brain region except spinal cord. Table 2 shows the associations between TDP-43 and $\mathrm{AD}$-related pathologies in each brain region. AD pathologies were strongly and positively associated with TDP-43 pathology in amygdala, hippocampus, and EC/ inferior TCTX, although the association between 


\section{Arteriolosclerosis pathology in human brain}
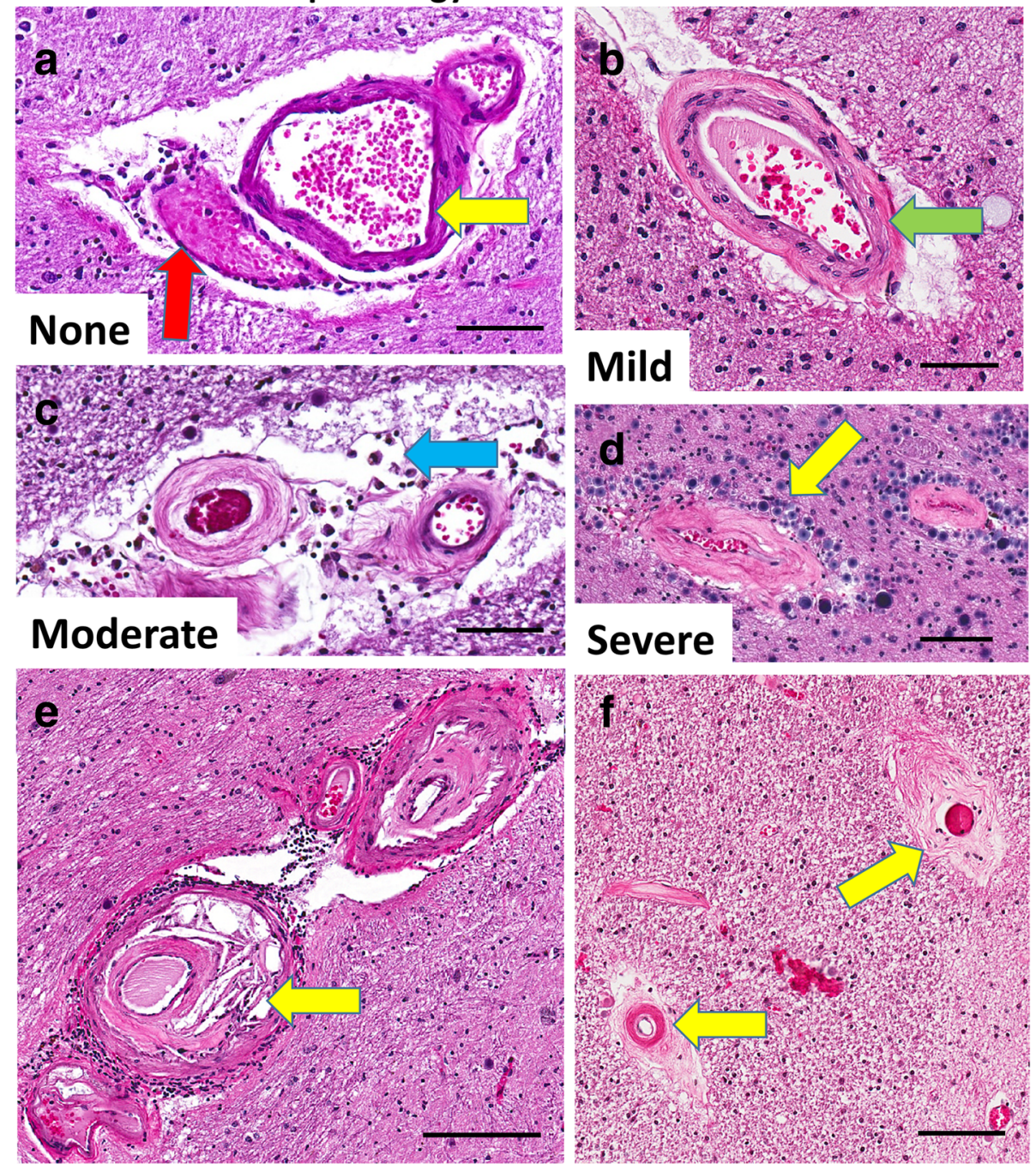

Fig. 2 Arteriolosclerosis pathology in the aged human brain. The present study used a 0-3 scale of severity for arteriolosclerosis pathology, which is illustrated in panels (a-d). These photomicrographs depict vascular profiles in sections of amygdala or peri-amygdaloid regions from aged individuals at various stages of arteriolosclerosis pathology. Panel (a) shows an arteriole (yellow arrow) next to a presumed venule (red arrow), which have histopathologic features within normal limits in aging, including some eosinophilic material in the vessel wall and Virchow-Robin space $\left.{ }^{*}\right]$ that may be partly an artifact of fixation and embedding. Panel (b) shows an arteriole with thicker vessel wall and intact cellular constituents, but with eosinophilic material (green arrow) in the adventitia. Panel (c) depicts arteriolosclerosis of moderate severity with some "onion-skinning" of the vessel wall and extravasation of macrophages (blue arrow) in the Virchow-Robin space. Panel (d) shows severe arteriolosclerosis in two vessels that have extensive proliferation of eosinophilic material in the vessel wall, attenuation of normal arteriolar cellular contents, apparent partial occlusion of the vessel itself, and the vessels are surrounded by corpora amylacea (yellow arrow) indicating localized brain injury. The pathologic appearance of brain arteriolosclerosis is heterogeneous, particularly in the area of the brain (amygdala; panels e,f) that is at high risk for incipient TDP-43 pathology. In panel (e), one can see pathologically affected blood vessel(s) with surrounding leukocytes and eosinophilic and small slit-like profiles that appear to be cholesterol clefts in the vessel wall. In panel (f), two vessels are seen (arrows) with largely attenuated cellular contents in the vessel walls. Scale bars $=150$ um (a,d); 100 um (b,c), 300 um (e), 250 um (f)

dichotomized diffuse plaques (moderate/frequent vs. no/ sparse) and TDP-43 pathology in hippocampus was not statistically significant. Among cerebrovascular disease pathologies, there were no significant associations (or even consistent trends) between TDP-43 pathology in any brain regions with atherosclerosis of the circle of
Willis, cerebral amyloid angiopathy, infarct and lacunes, microinfarcts, hemorrhages or microbleeds.

By contrast, arteriolosclerosis pathology was associated with TDP-43 pathology in amygdala and EC/inferior TCTX when adjusted for sex, age at death, APOE genotype, and the type of TDP-43 antibody. The significant 


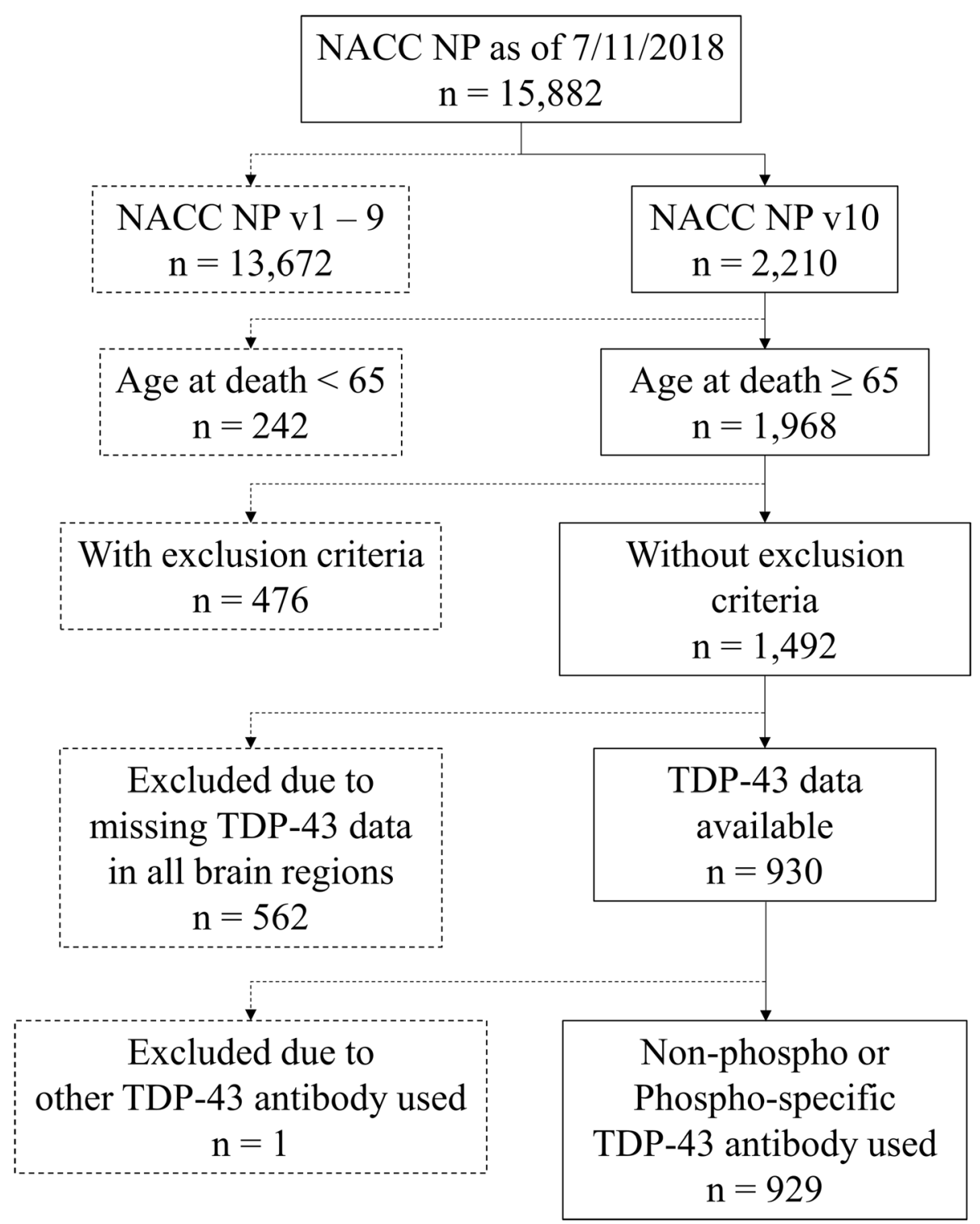

Fig. 3 Included study subjects for the present study. NACC = National Alzheimer's Coordinating Center; NP= Neuropathology

association in EC/inferior TCTX remained after AD-pathologies were added as covariates in the model (Table 3). To examine whether APOE genotype difference affects the association between TDP-43 pathology and arteriolosclerosis pathology, we further performed logistic regression analyses stratified by $A P O E$ genotype. As shown in Table 4, the associations of TDP-43 pathology in amygdala and EC/inferior TCTX with arteriolosclerosis pathology were observed in the subjects with $A P O E-/-$ or $-/ \varepsilon 4$ genotype. The significant association of TDP-43 in EC/inferior TCTX remained after including Thal $\mathrm{A} \beta$ phase and Braak NFT stage as additional covariates in the model. However, in persons with $A P O E$ $\varepsilon 4 / \varepsilon 4 \quad(n=77), \quad$ TDP-43 pathologies in amygdala, hippocampus, and frontal neocortex were not associated with arteriolosclerosis pathology.

\section{Discussion}

Here we present data focusing on TDP-43 pathology in the aged human brain, using a large sample with autopsy confirmation, sourced from multiple high-quality research centers. Our data provide new information about comorbidities that are and are not apparently associated with TDP-43 pathologies in different brain regions. TDP-43 pathology is strongly associated with advanced $\mathrm{AD}$ and brain arteriolosclerosis pathologies.

There are some potential pitfalls in our study sample, as we have discussed previously [3]. Contributory ADC 
Table 1 Characteristics of included study subjects

\begin{tabular}{|c|c|c|c|c|c|c|}
\hline Characteristic & $\begin{array}{l}\text { All included subjects } \\
(n=929)\end{array}$ & $\begin{array}{l}\text { No TDP-43 pathology } \\
(n=637)\end{array}$ & $\begin{array}{l}\text { TDP-43 pathology at } \\
\text { least one region } \\
(n=292)\end{array}$ & $P$-value ${ }^{b}$ & $\begin{array}{l}\text { Excluded subjects }{ }^{c} \\
(n=563)\end{array}$ & $P$-value ${ }^{d}$ \\
\hline Age at death, mean $\pm S D$ & $83.1 \pm 8.7$ & $82.4 \pm 8.8$ & $84.8 \pm 8.5$ & $<0.001$ & $84.4 \pm 9.0$ & 0.012 \\
\hline \multicolumn{7}{|l|}{ Gender, n (\%) } \\
\hline Male & $481(51.8)$ & $341(53.5)$ & $140(47.9)$ & \multirow[t]{2}{*}{0.13} & $287(51.0)$ & \multirow[t]{2}{*}{0.81} \\
\hline Female & $448(48.2)$ & $296(46.5)$ & $152(52.1)$ & & $276(49.0)$ & \\
\hline Education (years), mean $\pm S D$ & $15.5 \pm 3.1$ & $15.5 \pm 3.1$ & $15.5 \pm 3.2$ & 0.95 & $15.2 \pm 3.3$ & 0.10 \\
\hline \multicolumn{7}{|l|}{$A P O E, \mathrm{n}(\%)$} \\
\hline$-1-$ & $370(49.0)$ & $275(51.6)$ & $95(42.8)$ & \multirow[t]{3}{*}{0.063} & $229(52.8)$ & \multirow[t]{3}{*}{0.43} \\
\hline$-/ \varepsilon 4$ & $309(40.9)$ & $210(39.4)$ & $99(44.6)$ & & $162(37.3)$ & \\
\hline$\varepsilon 4 / \varepsilon 4$ & $76(10.1)$ & $48(9.0)$ & $28(12.6)$ & & $43(9.9)$ & \\
\hline \multicolumn{7}{|l|}{ Diabetes, n (\%) } \\
\hline Recent/remote & $91(15.5)$ & $66(15.6)$ & $25(15.2)$ & \multirow[t]{2}{*}{1} & $56(13.2)$ & \multirow[t]{2}{*}{0.35} \\
\hline Absent & $495(84.5)$ & $356(84.4)$ & $139(84.8)$ & & $368(86.8)$ & \\
\hline \multicolumn{7}{|l|}{ Hypertension, n (\%) } \\
\hline Recent/remote & $375(64.3)$ & $270(64.1)$ & $151(64.8)$ & \multirow[t]{2}{*}{0.95} & $281(67.9)$ & \multirow[t]{2}{*}{0.27} \\
\hline Absent & $208(35.7)$ & $105(35.9)$ & $57(35.2)$ & & $133(32.1)$ & \\
\hline \multicolumn{7}{|l|}{ Hypercholesterolemia, n (\%) } \\
\hline Recent/remote & $411(63.7)$ & $300(63.6)$ & $111(64.2)$ & \multirow[t]{2}{*}{0.96} & $297(66.4)$ & \multirow[t]{2}{*}{0.39} \\
\hline Absent & $234(36.3)$ & $172(36.4)$ & $62(35.8)$ & & $150(33.6)$ & \\
\hline \multicolumn{7}{|l|}{ Thyroid disease present, n (\%) } \\
\hline Yes & $70(24.4)$ & $48(24.5)$ & $22(24.2)$ & \multirow[t]{2}{*}{1} & $31(22.5)$ & \multirow[t]{2}{*}{0.75} \\
\hline No & $217(75.6)$ & $148(75.5)$ & $69(75.8)$ & & $107(77.5)$ & \\
\hline
\end{tabular}

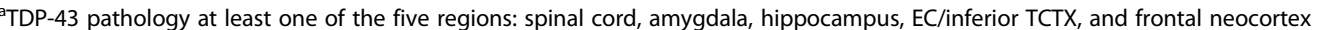

${ }^{b}$ The $p$-values were computed for the associations with TDP-43 inclusions statuses

'Subjects excluded due to missing TDP-43 data in all regions or other TDP-43 antibody used

${ }^{\mathrm{d}}$ The $p$-values were computed for the associations between all included subjects and the subjects with no data on TDP-43 inclusions

SD standard deviation

Bold $p$-value represents the statistical significance

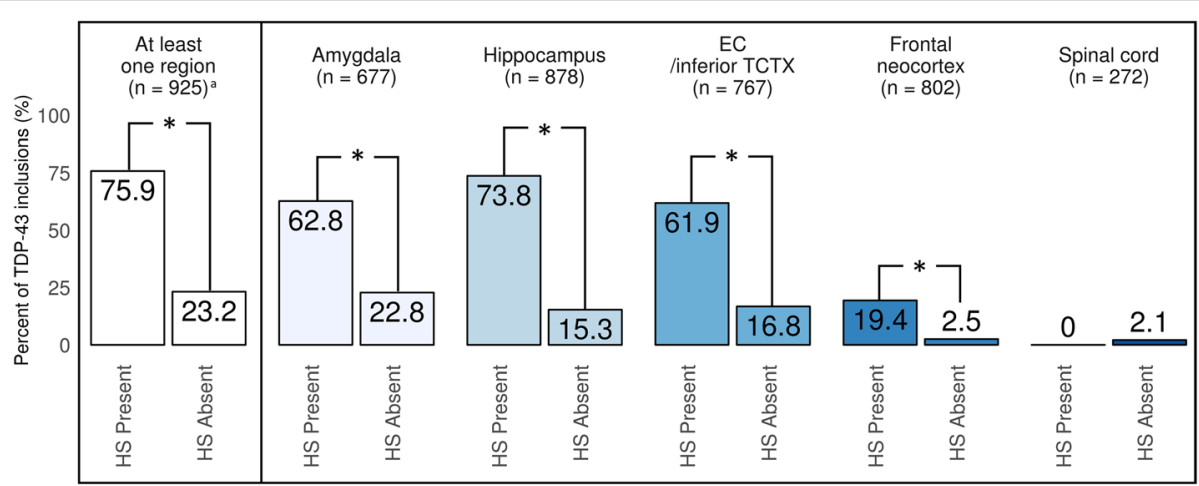

Fig. 4 Comparisons in percent of TDP-43 pathology in each brain region between hippocampal sclerosis present and absent. Note that there is a strong association between hippocampal sclerosis (HS) pathology and TDP-43 pathology. However, only a minority of cases, with or without comorbid HS pathology, have TDP-43 pathology detected in frontal cortex or spinal cord. ${ }^{a} n=4$ had missing data on hippocampal sclerosis (HS) pathology. ${ }^{*} p<0.001$. EC = entorhinal cortex; TCTX = temporal cortex 
Table 2 Associations between TDP-43 and Alzheimer's disease pathologies using binary logistic regression $(n=929)$

\begin{tabular}{lll}
\hline Region & OR $(95 \%$ Cl) & $P$-value \\
\hline Diffuse plaques (moderate + frequent vs. no + sparse) & \\
Amygdala & $3.34(1.47-8.99)$ & $\mathbf{0 . 0 0 7 9}$ \\
Hippocampus & $1.45(0.81-2.71)$ & 0.23 \\
EC/inferior TCTX & $2.61(1.20-6.53)$ & $\mathbf{0 . 0 2 5}$ \\
Frontal neocortex & $2.30(0.63-14.93)$ & 0.28
\end{tabular}

Neuritic plaques (moderate + frequent vs. no + sparse)

$\begin{array}{lll}\text { Amygdala } & 2.84(1.57-5.44) & \mathbf{9 . 1} \times \mathbf{1 0 ^ { - 4 }} \\ \text { Hippocampus } & 2.56(1.58-4.29) & \mathbf{2 . 2 \times 1 0 ^ { - 4 }} \\ \text { EC/inferior TCTX } & 4.04(2.11-8.43) & \mathbf{6 . 6 \times 1 0 ^ { - 5 }} \\ \text { Frontal neocortex } & 1.88(0.71-5.92) & 0.23\end{array}$

Thal $A \beta$ phase (phase $4+5$ vs. phase 0 to 3 )

$\begin{array}{lll}\text { Amygdala } & 2.78(1.56-5.21) & \mathbf{8 . 5} \times \mathbf{1 0}^{-\mathbf{4}} \\ \text { Hippocampus } & 2.34(1.44-3.93) & \mathbf{8 . 5} \times \mathbf{1 0 ^ { - 4 }} \\ \text { EC/inferior TCTX } & 2.52(1.41-4.77) & \mathbf{0 . 0 0 2 9} \\ \text { Frontal neocortex } & 1.42(0.53-4.50) & 0.51\end{array}$

Braak NFT stage (stage $\mathrm{V}+\mathrm{VI}$ vs. stage 0 to IV)

$\begin{array}{lll}\text { Amygdala } & 3.38(1.99-5.95) & \mathbf{1 . 3} \times \mathbf{1 0 ^ { - \mathbf { 5 } }} \\ \text { Hippocampus } & 2.90(1.86-4.63) & \mathbf{4 . 2} \times \mathbf{1 0 ^ { - 6 }} \\ \text { EC/inferior TCTX } & 3.15(1.86-5.53) & \mathbf{3 . 4} \times \mathbf{1 0}^{-\mathbf{5}} \\ \text { Frontal neocortex } & 1.22(0.52-3.06) & 0.66\end{array}$

adds ratios were adjusted for sex, age at death, APOE genotype, and the type of TDP-43 antibody

$O R$ odds ratio, $C l$ confidence interval, EC entorhinal cortex, TCTX temporal cortex, NFT neurofibrillary tangle

Bold $p$-value represents the statistical significance

cohorts tend to be enriched for rare, genetic, early-onset, and "pure" subtypes of diseases, including AD and many other degenerative conditions. In particular, this sample may be biased toward individuals with a clinical syndrome that mimics AD. The NACC-contributory ADCs also tend to recruit (and achieve autopsy consent for) Caucasian/white individuals of relatively high socioeconomic status; thus, there are relatively few non-Caucasian individuals or those lacking formal education. Further, ADCs apply exclusion criteria that can limit the number of autopsied participants with mental illness, substance abuse, physical disability, or other prevalent conditions. There also are challenges in data interpretation related to the lack of methodologic standardization between the ADCs in terms of TDP-43 IHC methods. This problem will probably plague multi-center studies for some time since our study confirms that different state-of-the-art research centers use different reagents to operationalize TDP-43 proteinopathy $(\sim 2$ / 3rd of ADCs use phospho-specific TDP-43 antibodies, whereas the remaining ADCs use antibodies that recognize non-phosphorylated epitopes). We also recognize the current lack of knowledge about
Table 3 Associations between TDP-43 and cerebrovascular disease pathologies using binary logistic regression $(n=929)$

\begin{tabular}{|c|c|c|c|c|}
\hline \multirow[t]{2}{*}{ Region } & \multicolumn{2}{|l|}{ Model $1^{a}$} & \multicolumn{2}{|l|}{ Model $2^{b}$} \\
\hline & OR $(95 \% \mathrm{Cl})$ & $P$-value & OR $(95 \% \mathrm{Cl})$ & $P$-value \\
\hline \multicolumn{5}{|c|}{ Atherosclerosis of the circle of Willis (moderate + severe vs. none + mild) } \\
\hline Amygdala & $0.96(0.63-1.47)$ & 0.87 & $0.90(0.58-1.39)$ & 0.63 \\
\hline Hippocampus & $1.07(0.74-1.55)$ & 0.70 & $0.98(0.67-1.43)$ & 0.93 \\
\hline EC/inferior TCTX & $1.16(0.77-1.75)$ & 0.48 & $1.07(0.70-1.62)$ & 0.77 \\
\hline Frontal neocortex & $1.03(0.47-2.27)$ & 0.93 & $1.00(0.45-2.21)$ & 0.99 \\
\hline
\end{tabular}

Cerebral amyloid angiopathy (moderate + severe vs. none + mild)

$\begin{array}{lllll}\text { Amygdala } & 0.82(0.52-1.28) & 0.38 & 0.66(0.41-1.04) & 0.077 \\ \text { Hippocampus } & 0.89(0.59-1.32) & 0.57 & 0.71(0.47-1.07) & 0.10 \\ \text { EC/inferior TCTX } & 0.99(0.64-1.52) & 0.97 & 0.79(0.50-1.22) & 0.29 \\ \text { Frontal neocortex } & 1.16(0.49-2.60) & 0.73 & 1.11(0.46-2.56) & 0.81 \\ \text { nfarct and lacunes (yes vs. no) } & & & \\ \text { Amygdala } & 0.77(0.43-1.32) & 0.35 & 0.84(0.47-1.45) & 0.54 \\ \text { Hippocampus } & 0.76(0.45-1.23) & 0.28 & 0.81(0.48-1.33) & 0.42 \\ \text { EC/inferior TCTX } & 0.79(0.45-1.32) & 0.38 & 0.87(0.49-1.48) & 0.61 \\ \text { Frontal neocortex } & 1.64(0.63-3.82) & 0.27 & 1.66(0.63-3.89) & 0.26\end{array}$

Microinfarcts (yes vs. no)

$\begin{array}{lllll}\text { Amygdala } & 1.15(0.73-1.79) & 0.55 & 1.08(0.68-1.70) & 0.74 \\ \text { Hippocampus } & 1.14(0.76-1.70) & 0.51 & 1.14(0.75-1.70) & 0.54 \\ \text { EC/inferior TCTX } & 1.25(0.80-1.94) & 0.31 & 1.21(0.77-1.88) & 0.41 \\ \text { Frontal neocortex } & 1.76(0.78-3.84) & 0.16 & 1.77(0.78-3.86) & 0.16\end{array}$

Hemorrhages and microbleeds (yes vs. no)

$\begin{array}{lllll}\text { Amygdala } & 0.65(0.26-1.44) & 0.32 & 0.65(0.25-1.47) & 0.33 \\ \text { Hippocampus } & 0.71(0.30-1.50) & 0.40 & 0.69(0.29-1.46) & 0.36 \\ \text { EC/inferior TCTX } & 0.57(0.21-1.29) & 0.21 & 0.55(0.20-1.26) & 0.19 \\ \text { Frontal neocortex } & 0.45(0.02-2.34) & 0.45 & 0.44(0.02-2.32) & 0.44\end{array}$

Arteriolosclerosis (moderate + severe vs. none + mild)

$\begin{array}{lllll}\text { Amygdala } & 1.56(1.03-2.37) & \mathbf{0 . 0 3 8} & 1.38(0.90-2.13) & 0.14 \\ \text { Hippocampus } & 1.31(0.92-1.89) & 0.14 & 1.16(0.80-1.69) & 0.42 \\ \text { EC/inferior TCTX } & 1.77(1.17-2.72) & \mathbf{0 . 0 0 7 8} & 1.61(1.05-2.49) & \mathbf{0 . 0 2 9} \\ \text { Frontal neocortex } & 0.97(0.45-2.13) & 0.95 & 0.93(0.43-2.06) & 0.86\end{array}$

adds ratios were adjusted for sex, age at death, APOE genotype, and the type of TDP-43 antibody used

${ }^{\mathrm{b}}$ Thal $A \beta$ phase and Braak NFT stage were included as additional covariates in model 2

$O R$ odds ratio, $C l$ confidence interval, EC entorhinal cortex, $T C T X$ temporal cortex Bold $p$-value represents the statistical significance

underlying mechanisms is a limitation, and our study does not describe how the brain arteriolosclerosis pathology spatially relates to the TDP-43 proteinopathy.

Despite the challenges and potential pitfalls, there also are considerable strengths related to this use of the NACC NP data set. We note that despite the abovementioned sources of data variability, our study found 
Table 4 Associations between TDP-43 and arteriolosclerosis (moderate/severe vs. none/mild) pathologies among included subjects stratified by $A P O E$ genotype

\begin{tabular}{|c|c|c|c|c|}
\hline \multirow[t]{2}{*}{ Region } & \multicolumn{2}{|c|}{$\begin{array}{l}A P O E-/- \text { or }-/ \varepsilon 4 \\
(n=679)^{\mathrm{a}}\end{array}$} & \multicolumn{2}{|l|}{$\begin{array}{l}\text { APOE } \varepsilon 4 / \varepsilon 4 \\
(n=76)^{\mathrm{a}}\end{array}$} \\
\hline & OR $(95 \% \mathrm{Cl})$ & $P$-value & OR $(95 \% \mathrm{Cl})$ & $P$-value \\
\hline \multicolumn{5}{|l|}{ Model $1^{b}$} \\
\hline Amygdala & $1.66(1.07-2.59)$ & 0.023 & $0.71(0.16-3.19)$ & 0.65 \\
\hline Hippocampus & $1.40(0.96-2.05)$ & 0.083 & $0.89(0.29-2.79)$ & 0.84 \\
\hline EC/inferior TCTX & $1.82(1.18-2.86)$ & 0.0080 & $1.43(0.35-6.55)$ & 0.62 \\
\hline Frontal neocortex & $1.13(0.50-2.61)$ & 0.76 & $0.26(0.01-3.04)$ & 0.30 \\
\hline \multicolumn{5}{|l|}{ Model $2^{c}$} \\
\hline Amygdala & $1.43(0.91-2.26)$ & 0.12 & $0.57(0.12-2.67)$ & 0.47 \\
\hline Hippocampus & 1.19 (0.80-1.77) & 0.39 & $0.80(0.25-2.56)$ & 0.70 \\
\hline EC/inferior TCTX & $1.60(1.02-2.54)$ & 0.041 & $1.13(0.27-5.26)$ & 0.87 \\
\hline Frontal neocortex & $1.08(0.47-2.52)$ & 0.86 & $0.21(0.01-2.47)$ & 0.23 \\
\hline
\end{tabular}

${ }^{\mathrm{a}} \mathrm{A}$ total of 755 subjects had data on APOE genotype (those data were missing in 174 subjects)

${ }^{b}$ Odds ratios were adjusted for sex, age at death, and the type of TDP-43 antibody used

'Thal A $\beta$ phase and Braak NFT stage were included as additional covariates in model 2

$O R$ odds ratio, $C l$ confidence interval, $E C$ entorhinal cortex, TCTX temporal cortex Bold $p$-value represents the statistical significance

evidence of strong associations between TDP-43 proteinopathy and other factors (age, HS pathology, AD pathology, and arteriolosclerosis pathology). These data were collected from individuals who died and came to autopsy over the past 4 years (NACC NP Form v10), providing both fresh data and relatively up-to-date clinical and pathological testing modalities. The study of nearly 1000 brains with $A P O E$ genotype and TDP-43 pathology status in multiple brain regions is unusual, and the statistical power it provides is important. Further, the derivation of data from 27 different research centers with expertise in research in AD and related dementias is a strength because the autopsy data may be considered more generalizable than the results from a single neuropathologist or small group of pathologists. For the foreseeable future, it seems unlikely that all research centers will agree on a single protocol for TDP-43 IHC, and we consider it a strength that the current study incorporates results from multiple research centers using site-specific protocols.

There are three main findings that we describe: TDP-43 pathology is strongly associated with advanced AD pathology; TDP-43 pathology is associated with increasingly severe arteriolosclerosis pathology (particularly in non $A P O E \quad \varepsilon 4 / \varepsilon 4$ carriers); and age-related TDP-43 pathology is predominantly seen in the medial temporal cortex, uncommon in frontal neocortex, and very rare in spinal cord.

There is a relatively large extant literature on the relatively common comorbidity of TDP-43 pathology with $\mathrm{AD}$, providing a compelling evidence that the pathologies co-occur whether or not they directly interact mechanistically [14, 16, 27, 30, 48]. Staging schema have been proposed to describe how TDP-43 pathology is distributed in brains with comorbid AD pathology [15, 17, 27]. Notably, in multiple cohorts of aged persons, TDP-43 pathology is more strongly linked to HS than early AD pathology [5, 7, 26, 28, 33]. However, within the amygdala of subjects with advanced $\mathrm{AD}$, protein misfolding (tau, $\mathrm{A} \beta, \alpha$-synuclein, and TDP-43 pathologies alike) tends to occur $[14,16]$.

Compared with $\mathrm{AD}$, the literature on the association between TDP-43 pathology and cerebrovascular is smaller, and overlaps with the paradigm of hypoxia/ischemia. As stated by Zarow et al. [49], "HS has long been hypothesized to result from ischemic-hypoxic insult to the brain. The CA1 sector is fed by small end-arterioles from the anterior choroidal and posterior cerebral arteries and is known to be susceptible to hypoxic injury" (with citation to Ref [9]). Others have also published data compatible with a link between HS pathology and cerebrovascular disease [22, 41, 46, 47, 49]. However, we have found in various data sets previous evidence of a relatively specific association between the type of HS that frequently is comborbid with TDP-43 pathology, and brain arteriolosclerosis [12, 35-37]. In the present study, the specificity of that association was underscored since no other subtype of cerebrovascular pathology was linked to TDP-43 pathology. There currently is no proven mechanistic explanation for this association. We note that factors that are conventionally associated with arteriolosclerosis, such as diabetes or hypertension, do not appear to be specifically associated with TDP-43 pathology. Intriguingly, Montagne and colleagues recently showed that subtle blood-brain barrier dysfunction and "leaky vessels" in the human hippocampus precede cognitive impairment in advanced aging [24]. Winkler et al. [42] reported that pericyte damage could contribute to cognitive impairment through disruption of the neurovascular unit, which may relate to TDP-43 proteinopathy, rather than $\mathrm{AD}$. There also have been described some genetic risk factors that may help explain the link between brain arteriolosclerosis and TDP-43 pathology [32], but more work is required in this area. We speculate that there may be some reason that the TDP- 43 pathology is usually confined to the medial temporal lobe of aged individuals, perhaps analogous to how primary age-related tauopathy [13], in the absence of comorbid $\mathrm{A} \beta$ plaques, tends not to progress beyond Braak NFT stage IV. Considering this analogy, there may be, in some of the brains, a disease-accelerating factor, analogous to $\mathrm{A} \beta$, which promotes TDP-43 pathology outside of the medial temporal lobe. 


\section{Additional file}

Additional file 1: Table S1. Exclusion criteria in the National Alzheimer's Coordination Center Neuropathology Form. Table S2. Missing frequency of TDP-43 pathology in each brain region collected on the National Alzheimer's Coordination Center Neuropathology Form version $10(n=929)$. Table S3. Variables for Alzheimer's disease and cerebrovascular disease pathologies in the National Alzheimer's Coordination Center Neuropathology Form version 10. Table S4. Frequency of TDP-43 antibody used in each Alzheimer's Disease Center. (PDF 181 kb)

\section{Acknowledgments}

We are extremely grateful to the many patients, clinicians, and other colleagues, who have worked so hard to provide and organize these data. The NACC database is funded by NIA/NIH Grant U01 AG016976. NACC data are contributed by the NIA-funded ADCs: P30 AG019610 (PI Eric Reiman, MD), P30 AG013846 (PI Neil Kowall, MD), P50 AG008702 (PI Scott Small, MD), P50 AG025688 (PI Allan Levey, MD, PhD), P50 AG047266 (PI Todd Golde, MD, PhD), P30 AG010133 (PI Andrew Saykin, PsyD), P50 AG005146 (PI Marilyn Albert, PhD), P50 AG005134 (PI Bradley Hyman, MD, PhD), P50 AG016574 (PI Ronald Petersen, MD, PhD), P50 AG005138 (PI Mary Sano, PhD), P30 AG008051 (PI Thomas Wisniewski, MD), P30 AG013854 (PI M. Marsel Mesulam, MD), P30 AG008017 (PI Jeffrey Kaye, MD), P30 AG010161 (PI David Bennett, MD), P50 AG047366 (PI Victor Henderson, MD, MS), P30 AG010129 (PI Charles DeCarli, MD), P50 AG016573 (PI Frank LaFerla, PhD), P50 AG005131 (PI James Brewer, MD, PhD), P50 AG023501 (PI Bruce Miller, MD), P30 AG035982 (PI Russell Swerdlow, MD), P30 AG028383 (PI Linda Van Eldik, PhD), P30 AG053760 (PI Henry Paulson, MD, PhD), P30 AG010124 (PI John Trojanowski, MD, PhD), P50 AG005133 (PI Oscar Lopez, MD), P50 AG005142 (PI Helena Chui, MD), P30 AG012300 (PI Roger Rosenberg, MD), P30 AG049638 (PI Suzanne Craft, PhD), P50 AG005136 (PI Thomas Grabowski, MD), P50 AG033514 (PI Sanjay Asthana, MD, FRCP), P50 AG005681 (PI John Morris, MD), P50 AG047270 (PI Stephen Strittmatter, MD, PhD).

\section{Funding}

Funding included NIH grants P30 AG028383, R01 AG057187, R01 AG042475, R01 AG054060, and U01 AG016976 from the National Institute on Aging (NIA)/National Institutes of Health (NIH). For more on NACC-related funding, please see Acknowledgment section.

\section{Availability of data and materials}

All data generated or analysed during this study are included in this published article [and its additional files].

\section{Authors' contributions}

Acquisition, analysis and interpretation of the data: YK, PTN. Manuscript preparation and conceptualization: YK, PTN. Critical revision of the manuscript for intellectual content: PTN, DWF, WAK. All authors read and approved the final manuscript.

\section{Ethics approval and consent to participate}

Research using the National Alzheimer's Coordinating Center database was approved by the University of Washington Institutional Review Board. Informed consent was obtained from all participants at the individual Alzheimer's Disease Centers.

\section{Consent for publication}

Not applicable

\section{Competing interests}

The authors declare that they have no competing interests.

\section{Publisher's Note}

Springer Nature remains neutral with regard to jurisdictional claims in published maps and institutional affiliations.

\section{Author details}

'Department of Biostatistics, University of Kentucky, 725 Rose Street, Lexington, KY 40536, USA. ${ }^{2}$ Sanders-Brown Center on Aging, University of
Kentucky, Lexington, KY 40536, USA. ${ }^{3}$ National Alzheimer's Coordinating Center, Department of Epidemiology, University of Washington, Seattle, WA 98105, USA. Department of Pathology, Division of Neuropathology, University of Kentucky, Lexington, KY 40536, USA.

Received: 27 November 2018 Accepted: 29 November 2018

Published online: 19 December 2018

\section{References}

1. Amador-Ortiz C, Dickson DW (2008) Neuropathology of hippocampal sclerosis. Handb Clin Neurol 89:569-572. https://doi.org/10.1016/S00729752(07)01253-5

2. Amador-Ortiz C, Lin WL, Ahmed Z, Personett D, Davies P, Duara R, GraffRadford NR, Hutton ML, Dickson DW (2007) TDP-43 immunoreactivity in hippocampal sclerosis and Alzheimer's disease. Ann Neurol 61:435-445. https://doi.org/10.1002/ana.21154

3. Besser LM, Kukull WA, Teylan MA, Bigio EH, Cairns NJ, Kofler JK, Montine TJ, Schneider JA, Nelson PT (2018) The revised National Alzheimer's coordinating Center's neuropathology form-available data and new analyses. J Neuropathol Exp Neurol 77:717-726. https://doi.org/10.1093/ jnen/nly049

4. Braak H, Ludolph AC, Neumann M, Ravits J, Del Tredici K (2017) Pathological TDP-43 changes in Betz cells differ from those in bulbar and spinal alphamotoneurons in sporadic amyotrophic lateral sclerosis. Acta Neuropathol 133:79-90. https://doi.org/10.1007/s00401-016-1633-2

5. Brenowitz WD, Monsell SE, Schmitt FA, Kukull WA, Nelson PT (2014) Hippocampal sclerosis of aging is a key Alzheimer's disease mimic: clinicalpathologic correlations and comparisons with both alzheimer's disease and non-tauopathic frontotemporal lobar degeneration. J Alzheimers Dis 39: 691-702. https://doi.org/10.3233/JAD-131880

6. Brettschneider J, Del Tredici K, Toledo JB, Robinson JL, Irwin DJ, Grossman M, Suh E, Van Deerlin VM, Wood EM, Baek Y et al (2013) Stages of pTDP-43 pathology in amyotrophic lateral sclerosis. Ann Neurol 74:20-38. https://doi. org/10.1002/ana.23937

7. Cykowski MD, Takei H, Van Eldik LJ, Schmitt FA, Jicha GA, Powell SZ, Nelson PT (In Press) Hippocampal sclerosis, but not normal aging or Alzheimer's disease, is associated iwth TDP-43 pathology in aged persons' basal forebrain. J Neuropathol Exp Neurol

8. Dickson DW, Davies P, Bevona C, Van Hoeven KH, Factor SM, Grober E, Aronson MK, Crystal HA (1994) Hippocampal sclerosis: a common pathological feature of dementia in very old ( $>$ or $=80$ years of age) humans. Acta Neuropathol 88:212-221

9. Duvernoy HM (2005) The human Hippocampus: functional anatomy, vascularization and serial sections with MRI. Srpinger-Verlag, City

10. Fatima M, Tan R, Halliday GM, Kril JJ (2015) Spread of pathology in amyotrophic lateral sclerosis: assessment of phosphorylated TDP-43 along axonal pathways. Acta Neuropathol Commun 3:47. https://doi.org/10.1186/ s40478-015-0226-y

11. Geser F, Robinson JL, Malunda JA, Xie SX, Clark CM, Kwong LK, Moberg PJ, Moore EM, Van Deerlin VM, Lee VM et al (2010) Pathological 43-kDa transactivation response DNA-binding protein in older adults with and without severe mental illness. Arch Neurol 67:1238-1250. https://doi.org/10. 1001/archneurol.2010.254

12. Ighodaro ET, Abner EL, Fardo DW, Lin AL, Katsumata Y, Schmitt FA, Kryscio RJ, Jicha GA, Neltner JH, Monsell SE et al (2017) Risk factors and global cognitive status related to brain arteriolosclerosis in elderly individuals. Cereb Blood Flow Metab 37:201-216. https://doi.org/10.1177/ $0271678 \times 15621574$

13. Jellinger KA, Alafuzoff I, Attems J, Beach TG, Cairns NJ, Crary JF, Dickson DW, Hof PR, Hyman BT, Jack CR Jr et al (2015) PART, a distinct tauopathy, different from classical sporadic Alzheimer disease. Acta Neuropathol 129: 757-762. https://doi.org/10.1007/s00401-015-1407-2

14. Josephs KA, Dickson DW, Tosakulwong N, Weigand SD, Murray ME, Petrucelli L, Liesinger AM, Senjem ML, Spychalla AJ, Knopman DS et al (2017) Rates of hippocampal atrophy and presence of post-mortem TDP-43 in patients with Alzheimer's disease: a longitudinal retrospective study. Lancet Neurol 16:917-924. https://doi.org/10.1016/S1474-4422(17)30284-3

15. Josephs KA, Murray ME, Whitwell JL, Parisi JE, Petrucelli L, Jack CR, Petersen RC, Dickson DW (2014) Staging TDP-43 pathology in Alzheimer's disease. Acta Neuropathol 127:441-450. https://doi.org/10.1007/s00401-013-1211-9 
16. Josephs KA, Murray ME, Whitwell $J$, Tosakulwong N, Weigand SD, Petrucelli L, Liesinger AM, Petersen RC, Parisi JE, Dickson DW (2016) Updated TDP-43 in Alzheimer's disease staging scheme. Acta Neuropathol 131:571-585. https://doi.org/10.1007/s00401-016-1537-1

17. Josephs KA, Murray ME, Whitwell $\mathrm{L}$, Tosakulwong N, Weigand SD, Petrucelli L, Liesinger AM, Petersen RC, Parisi JE, Dickson DW (2016) Updated TDP-43 in Alzheimer's disease staging scheme. Acta Neuropathol. https://doi.org/10. 1007/s00401-016-1537-1

18. Josephs KA, Whitwell JL, Knopman DS, Hu WT, Stroh DA, Baker M, Rademakers R, Boeve BF, Parisi JE, Smith GE et al $(2008,1850)$ Abnormal TDP-43 immunoreactivity in AD modifies clinicopathologic and radiologic phenotype. Neurology 70:-1857. https://doi.org/10.1212/01.wnl.0000304041. 09418.b1

19. Kero M, Raunio A, Polvikoski T, Tienari PJ, Paetau A, Myllykangas L (2018) Hippocampal sclerosis in the oldest old: a Finnish population-based study. J Alzheimers Dis 63:263-272. https://doi.org/10.3233/JAD-171068

20. Lee EB, Lee VM, Trojanowski JQ, Neumann M (2008) TDP-43 immunoreactivity in anoxic, ischemic and neoplastic lesions of the central nervous system. Acta Neuropathol 115:305-311. https://doi.org/10.1007/ s00401-007-0331-5

21. Leverenz JB, Agustin CM, Tsuang D, Peskind ER, Edland SD, Nochlin D, DiGiacomo L, Bowen JD, McCormick WC, Teri L et al (2002) Clinical and neuropathological characteristics of hippocampal sclerosis: a communitybased study. Arch Neurol 59:1099-1106

22. Leverenz JB, Lipton AM (2008) Clinical aspects of hippocampal sclerosis. Handb Clin Neurol 89:565-567. https://doi.org/10.1016/S00729752(07)01252-3

23. Mackenzie IR, Neumann M, Bigio EH, Cairns NJ, Alafuzoff I, Kril J, Kovacs GG, Ghetti B, Halliday G, Holm IE et al (2010) Nomenclature and nosology for neuropathologic subtypes of frontotemporal lobar degeneration: an update. Acta Neuropathol 119:1-4. https://doi.org/10.1007/s00401-009-0612-2

24. Montagne A, Barnes SR, Sweeney MD, Halliday MR, Sagare AP, Zhao Z, Toga AW, Jacobs RE, Liu CY, Amezcua L et al (2015) Blood-brain barrier breakdown in the aging human hippocampus. Neuron 85:296-302. https:// doi.org/10.1016/j.neuron.2014.12.032

25. Montine TJ, Phelps CH, Beach TG, Bigio EH, Cairns NJ, Dickson DW, Duyckaerts C, Frosch MP, Masliah E, Mirra SS et al (2012) National Institute on Aging-Alzheimer's Association guidelines for the neuropathologic assessment of Alzheimer's disease: a practical approach. Acta Neuropathol 123:1-11. https://doi.org/10.1007/s00401-011-0910-3

26. Murray ME, Cannon A, Graff-Radford NR, Liesinger AM, Rutherford NJ, Ross OA, Duara R, Carrasquillo MM, Rademakers R, Dickson DW (2014) Differential clinicopathologic and genetic features of late-onset amnestic dementias. Acta Neuropathol 128:411-421. https://doi.org/10.1007/s00401-014-1302-2

27. Nag S, Yu L, Boyle PA, Leurgans SE, Bennett DA, Schneider JA (2018) TDP-43 pathology in anterior temporal pole cortex in aging and Alzheimer's disease. Acta Neuropathol Commun 6:33. https://doi.org/10.1186/s40478018-0531-3

28. Nag S, Yu L, Capuano AW, Wilson RS, Leurgans SE, Bennett DA, Schneider JA (2015) Hippocampal sclerosis and TDP-43 pathology in aging and Alzheimer disease. Ann Neurol 77:942-952. https://doi.org/10.1002/ana. 24388

29. Nag S, Yu L, Wilson RS, Chen EY, Bennett DA, Schneider JA (2017) TDP-43 pathology and memory impairment in elders without pathologic diagnoses of AD or FTLD. Neurology 88:653-660. https://doi.org/10.1212/WNL. 0000000000003610

30. Nelson PT, Abner EL, Patel E, Anderson S, Wilcock DM, Kryscio RJ, Van Eldik L, Jicha GA, Gal Z, Nelson RS et al (2018) The amygdala as a locus of pathologic Misfolding in neurodegenerative diseases. J Neuropathol Exp Neurol 77:2-20. https://doi.org/10.1093/jnen/nlx099

31. Nelson PT, Abner EL, Schmitt FA, Kryscio RJ, Jicha GA, Smith CD, Davis DG, Poduska JW, Patel E, Mendiondo MS et al (2010) Modeling the association between 43 different clinical and pathological variables and the severity of cognitive impairment in a large autopsy cohort of elderly persons. Brain Pathol 20:66-79. https://doi.org/10.1111/j.1750-3639.2008.00244.x

32. Nelson PT, Jicha GA, Wang WX, Ighodaro E, Artiushin S, Nichols CG, Fardo DW (2015) ABCC9/SUR2 in the brain: implications for hippocampal sclerosis of aging and a potential therapeutic target. Ageing Res Rev 24:111-125. https://doi.org/10.1016/j.arr.2015.07.007

33. Nelson PT, Schmitt FA, Lin Y, Abner EL, Jicha GA, Patel E, Thomason PC, Neltner JH, Smith CD, Santacruz KS et al (2011) Hippocampal sclerosis in advanced age: clinical and pathological features. Brain 134:1506-1518 https://doi.org/10.1093/brain/awr053

34. Nelson PT, Smith CD, Abner EL, Wilfred BJ, Wang WX, Neltner JH, Baker M, Fardo DW, Kryscio RJ, Scheff SW et al (2013) Hippocampal sclerosis of aging, a prevalent and high-morbidity brain disease. Acta Neuropathol 126: 161177 https://doi.org/10.1007/s00401-013-1154-1

35. Nelson PT, Trojanowski JQ, Abner EL, Al-Janabi OM, Jicha GA, Schmitt FA, Smith CD, Fardo DW, Wang WX, Kryscio RJ et al (2016) "new old pathologies": AD, PART, and cerebral age-related TDP-43 with sclerosis (CARTS). J Neuropathol Exp Neurol 75:482-498. https://doi.org/10.1093/jnen/ nlw033

36. Neltner JH, Abner EL, Baker S, Schmitt FA, Kryscio RJ, Jicha GA, Smith CD, Hammack E, Kukull WA, Brenowitz WD et al (2014) Arteriolosclerosis that affects multiple brain regions is linked to hippocampal sclerosis of ageing. Brain 137:255-267. https://doi.org/10.1093/brain/awt318

37. Neltner JH, Abner EL, Jicha GA, Schmitt FA, Patel E, Poon LW, Marla G, Green RC, Davey A, Johnson MA et al (2016) Brain pathologies in extreme old age. Neurobiol Aging 37:1-11. https://doi.org/10.1016/j.neurobiolaging. 2015.10.009

38. Neumann M, Sampathu DM, Kwong LK, Truax AC, Micsenyi MC, Chou TT, Bruce J, Schuck T, Grossman M, Clark CM et al (2006) Ubiquitinated TDP-43 in frontotemporal lobar degeneration and amyotrophic lateral sclerosis. Science 314:130-133. https://doi.org/10.1126/science.1134108

39. Pao WC, Dickson DW, Crook JE, Finch NA, Rademakers R, Graff-Radford NR (2011) Hippocampal sclerosis in the elderly: genetic and pathologic findings, some mimicking Alzheimer disease clinically. Alzheimer Dis Assoc Disord 25:364-368. https://doi.org/10.1097/WAD.0b013e31820f8f50

40. R Development Core Team (2013) R: a language and environment for statistical computing. 3.0.2 edn. R. Foundation for Statistical Computing, City

41. Reed BR, Mungas DM, Kramer JH, Ellis W, Vinters HV, Zarow C, Jagust WJ, Chui HC (2007) Profiles of neuropsychological impairment in autopsydefined Alzheimer's disease and cerebrovascular disease. Brain 130:731-739. https://doi.org/10.1093/brain/awl385

42. Sagare AP, Bell RD, Zhao Z, Ma Q, Winkler EA, Ramanathan A, Zlokovic BV (2013) Pericyte loss influences Alzheimer-like neurodegeneration in mice. Nat Commun 4:2932. https://doi.org/10.1038/ncomms3932

43. Thal DR, Attems J, Ewers M (2014) Spreading of amyloid, tau, and microvascular pathology in Alzheimer's disease: findings from neuropathological and neuroimaging studies. J Alzheimers Dis 42(Suppl 4): S421-S429. https://doi.org/10.3233/JAD-141461

44. Uchino A, Takao M, Hatsuta H, Sumikura H, Nakano Y, Nogami A, Saito Y, Arai T, Nishiyama K, Murayama S (2015) Incidence and extent of TDP-43 accumulation in aging human brain. Acta Neuropathol Commun 3:35. https://doi.org/10.1186/s40478-015-0215-1

45. Verde F, Del Tredici K, Braak H, Ludolph A (2017) The multisystem degeneration amyotrophic lateral sclerosis - neuropathological staging and clinical translation. Arch Ital Biol 155:118-130. https://doi.org/10.12871/ 00039829201746

46. White $L$ (2009) Brain lesions at autopsy in older Japanese-American men as related to cognitive impairment and dementia in the final years of life: a summary report from the Honolulu-Asia aging study. J Alzheimers Dis 18: 713-725. https://doi.org/10.3233/JAD-2009-1178

47. White L, Petrovitch H, Hardman J, Nelson J, Davis DG, Ross GW, Masaki K, Launer L, Markesbery WR (2002) Cerebrovascular pathology and dementia in autopsied Honolulu-Asia aging study participants. Ann N Y Acad Sci 977: 9-23

48. Yang HS, Yu L, White CC, Chibnik LB, Chhatwal JP, Sperling RA, Bennett DA, Schneider JA, De Jager PL (2018) Evaluation of TDP-43 proteinopathy and hippocampal sclerosis in relation to APOE epsilon4 haplotype status: a community-based cohort study. Lancet Neurol 17:773-781. https://doi.org/ 10.1016/S1474-4422(18)30251-5

49. Zarow C, Sitzer TE, Chui HC (2008) Understanding hippocampal sclerosis in the elderly: epidemiology, characterization, and diagnostic issues. Curr Neurol Neurosci Rep 8:363-370

50. Zarow C, Weiner MW, Ellis WG, Chui HC (2012) Prevalence, laterality, and comorbidity of hippocampal sclerosis in an autopsy sample. Brain Behavior 2:435-442. https://doi.org/10.1002/brb3.66 